\title{
BMJ Open Exploration of the psychometric properties of the Person-Centred Primary Care Measure (PCPCM) in a Chinese primary care population in Hong Kong: a cross- sectional validation study
}

\author{
Emily Tsui Yee Tse (10 , 1,2 Cindy Lo Kuen Lam, ${ }^{1,2}$ Carlos King Ho Wong (D) ,2,3 \\ Weng Yee Chin (D) , ${ }^{2}$ Rebecca S Etz, ${ }^{4}$ Stephen J Zyzanski, ${ }^{5}$ Kurt C Stange ${ }^{5}$
}

To cite: Tse ETY, Lam CLK, Wong CKH, et al. Exploration of the psychometric properties of the Person-Centred Primary Care Measure (PCPCM) in a Chinese primary care population in Hong Kong: a cross-sectional validation study. BMJ Open 2021;11:e052655. doi:10.1136/ bmjopen-2021-052655

- Prepublication history and additional supplemental materia for this paper are available online. To view these files, please visit the journal online (http://dx.doi.org/10.1136/ bmjopen-2021-052655)

Received 23 April 2021 Accepted 26 August 2021

Check for updates

(c) Author(s) (or their employer(s)) 2021. Re-use permitted under CC BY-NC. No commercial re-use. See rights and permissions. Published by BMJ.

For numbered affiliations see end of article.

Correspondence to Dr Emily Tsui Yee Tse; emilyht@hku.hk

\section{ABSTRACT}

Objectives To evaluate the validity and psychometric properties of the Chinese Person-Centred Primary Care Measure (PCPCM) in a Chinese-speaking population. Design A cross-sectional study.

Setting A primary care clinic in Hong Kong. Participants 300 Chinese adult patients ( 150 males and 150 females) were recruited from a primary care clinic to complete a questionnaire containing the PCPCM, Consultation and Relational Empathy (CARE), Patient Enablement Index (PEI) and Adult (short version) Primary Care Assessment Tool (PCAT). The Chinese PCPCM was readministered to 118 participants after 14 days for testretest reliability.

Outcome measures The construct validity, reliability and sensitivity of the Chinese PCPCM.

Results The Chinese PCPCM was identified to have a one-factor construct, with good item fit and unidimensionality on Rasch analysis. Internal reliability was high (Cronbach's alpha $>0.8$ ) with moderate testretest reliability (intraclass correlation coefficient $=0.622$, $\mathrm{p}<0.001)$. Significant correlations $(0.58,0.42,0.48)$ between the PCPCM and CARE, PEl and Adult (short version) PCAT scores supported good convergent construct validity. PCPCM scores were higher among patients who had known their doctors for a longer period or who were more likely to be able to see the same doctor at every visit, and among those who self-reported to have 'better health' rather than 'worse health'.

Conclusion The Chinese PCPCM appears to be a valid, reliable and sensitive instrument for evaluating the quality of person-centred care among primary care patients in Hong Kong. Further studies are needed to confirm the utility of this instrument in other Chinese-speaking populations around the world.

\section{BACKGROUND}

In 2018, WHO and the UNICEF jointly published the document 'A Vision for Primary Health Care in the 21st Century'. This document presented a modern concept of Primary Health Care as 'a whole-of-society

\section{STRENGTHS AND LIMITATIONS OF THIS STUDY}

$\Rightarrow$ This is the first study to validate the Person-Centred Primary Care Measure (PCPCM) in a Chinesespeaking population following its translation from English to Chinese.

$\Rightarrow$ Validation of the PCPCM in a Chinese population is the first step towards ensuring the applicability and reliability of the instrument in multinational settings enabling multicentre studies and cross-cultural comparisons.

$\Rightarrow$ Correlations with the Consultation and Relational Empathy, Patient Enablement Index and the Patient Care Assessment Tool instruments were examined confirming the convergent and construct validity of the PCPCM.

$\Rightarrow$ Subjects were recruited from one primary care clinic in Hong Kong, and were all Cantonese Chinese speakers which may limit the generalisability of these findings to non-Cantonese-speaking Chinese populations.

$\Rightarrow$ The methods used for baseline (face-to-face interviews) and follow-up (telephone interviews) data collection were not standardised which can potentially impact the results of test-retest reliability.

approach to health that aims to ensure the highest possible level of health and well-being and their equitable distribution by focusing on people's needs and preferences (as individuals, families and communities) as early as possible along the continuum from health promotion and disease prevention to treatment, rehabilitation and palliative care, and as close as feasible to people's everyday environment. ${ }^{1}$ This vision placed 'people' as the central focus in primary care. Starfield made a clear statement in 2011 to build up the concept of 'person-centredness' from 'patientcentredness' in healthcare. She stated 'Both patient-centred and person-focused care are 
important, but they are different. In contrast to patientcentred care (at least as described in the current literature with assessments that are visit-based), person-focused care is based on accumulated knowledge of people, which provides the basis for better recognition of health problems and needs over time and facilitates appropriate care for these needs in the context of other needs. That is, it specifically focuses on the whole person. ${ }^{2}$ In order to assess whether primary care practices are performing in the internationally agreed direction as mentioned above, a measure is needed that can comprehensively reflect the 'people-centred value' of primary care practices. This measure should not only assess the efficacy of clinical processes and outcomes, but also value the higher-level functions of primary care including its ability to integrate, personalise and prioritise care, yet simple enough to facilitate its clinical use. ${ }^{3}$ The 11-item Person-Centred Primary Care Measure (PCPCM) (online supplemental file 1), was developed by Etz et al for this purpose.

PCPCM was generated following extensive surveys among patients, primary care clinicians and healthcare payers to describe what provides value in primary care, followed by additional insights given by primary care experts in the Starfield Summit III, focusing "what matters in primary care'. It is a patient self-reported outcome measure consisting of 11 items rated on a 4-point Likert scale. The PCPCM score is computed as the mean of the items that were answered. The measure underwent three sets of psychometric analyses to identify its construct and confirm its reliability and concurrent validity. ${ }^{3}$ The PCPCM evaluates 11 domains, each by a single item, on accessibility, advocacy, community context, comprehensiveness, continuity, coordination, family context, goal-oriented care, health promotion, integration and relationship. ${ }^{3}$ It provides a practical approach that allows the breadth of person-centred primary care to be assessed in one simple measure.

The PCPCM has been tested in many countries including 35 Organisation for Economic Co-operation and Development (OECD) countries, and in 28 different languages. ${ }^{4}$ Despite its widespread testing in OECD countries, the PCPCM has yet to be tested on a Chinese population whose culture may be very different from other OECD countries. Chinese is the most-spoken first language in the world: $12.3 \%$ of global population are using Chinese as their mother tongue. ${ }^{5}$ A Chinese translation of the PCPCM can facilitate its use in the evaluation of the quality of person-centred primary care for Chinese people around the world. We had developed a Chinese translation of the PCPCM (online supplemental file 2) and confirmed its content validity through cognitive debriefing in an earlier study. ${ }^{6}$ The aim of this study was to evaluate the construct validity and psychometric properties of the PCPCM among Chinese patients in a clinical setting.

In Hong Kong, 92\% of the population are ethnically Chinese. Eighty-nine per cent use the Cantonese dialect as their first language. ${ }^{7}$ Although people may speak different dialects, all Chinese share the same written language. Results showing the validity and reliability of the PCPCM in the Hong Kong Chinese population may support its applicability in other Chinese-speaking settings.

\section{METHODS}

\section{Subject recruitment}

A total of 300 subjects were recruited by purposive sampling from a public-sector primary care clinic in Hong Kong from August to December 2019. The inclusion criteria were (1) patients aged 18 years or above; (2) could read Chinese and (3) could give written consent to participate in this study. Patients who could not communicate in Cantonese, were too ill to complete the questionnaire or refused to participate were excluded. Public primary care clinics in Hong Kong are open to all residents to receive primary care services at a very low cost ( $£ 5$ per consultation including medications and investigations). The subject recruitment site of this study was an average size public primary care clinic with a patient profile similar to those of other public primary care clinics across Hong Kong. The distribution of the consultations was $70 \%$ chronic disease follow-up (mostly for hypertension and diabetes mellitus) and 30\% episodic illnesses. A total of 12 family physicians were regularly working in the clinic during the period of subject recruitment. Their clinical experience ranged from third year trainee in family medicine to family medicine specialist with more than 30 practice-years. Majority of the doctors were family medicine specialists with more than 10 years' practice experience. All doctors speak Cantonese and $99 \%$ of the consultations are conducted in this dialect.

Subjects were purposively sampled to achieve a balance between gender and reason for consultation (ie, chronic follow-up vs episodic visit). The aim, procedures and nature of the study were explained to patients. Time was allowed for them to raise any questions regarding the study purpose and procedures. Written consent was obtained. All subjects were invited for a follow-up phone call 2 weeks after the initial interview to readminister the PCPCM to assess test-retest reliability and for crossvalidation of the Rasch analysis. As the baseline interview (to complete the whole set of questionnaires including the demographics, PCPCM, CARE, Patient Enablement Index (PEI) and Primary Care Assessment Tool (PCAT)) was expected to last for 15-30 min, each subject was given a HK\$100 ( £10) supermarket voucher as a token of appreciation for his/her time.

\section{Study instruments \\ PCPCM in Chinese}

The PCPCM contains 11 items as described above, each is rated on a 4-point Likert scale: 1 (not at all); 2 (somewhat); 3 (mostly) to 4 (definitely), with higher scores indicating patients reporting a greater frequency of experiencing the specific domain of primary care. ${ }^{3}$ Responses with missing data from more than three items are considered 
as invalid and hence excluded from further analysis. We took three as the maximal tolerance of missing items based on the belief that by answering 8 out of the 11 items, a majority $(73 \%)$ of the 11 components of primary care covered by the measure would have been addressed. If a higher number of missing items was allowed, that would risk important components of primary care not being addressed and the overall PCPCM score (based on the number of answered items) would likely to be more variable. The overall PCPCM score is computed as the mean of the items that were answered with a range from 1.0 to 4.0. The Measure has a supplementary question asking the duration (in years) that the patient has known the doctor for.

The following three patient-reported measures were used to collect data for testing convergent construct validity:

\section{Consultation and Relational Empathy}

The Consultation and Relational Empathy (CARE) Measure was developed as a process measure of the consultation, based on a broad definition of empathy. ${ }^{8-10}$ A Chinese version has already been proved to be reliable and valid in primary care in Hong Kong. ${ }^{11}$ It contains 10 items rated on a 5-point Likert scale ranging from 1 (poor) to 5 (excellent) which are summed together into a total score ranging from 10 to 50 . Missing values or 'not applicable' responses of up to two items can be replaced with the average score of the answered items. Cases with missing or not applicable more than two items are excluded. The higher the score, the more satisfied is the patient in terms of relational empathy and communication in the consultation.

\section{Patient Enablement Index}

The PEI was developed by Howie et al ${ }^{12}$ to measure patients' enablement, which is an indicator of the effectiveness of a primary care consultation. A Chinese version was shown to be valid, reliable with good sensitivity. ${ }^{13}$ The instrument contains six items, each rated by responses of 'much better/much more', 'better/more', 'same or 'less' were scored 2, 1 and 0 , respectively. The PEI score was calculated by the mean of the scores of the applicable items multiplied by six. Cases that had 'not applicable' responses in more than three items were excluded. The total PEI score ranges from 0 to 12. A higher score reflects higher patient enablement perceived.

\section{Adult (short version) PCAT}

The PCAT assesses the performance of facilities and systems from multiple perspectives and faithfully parallels WHO's definition of primary care. ${ }^{14}{ }^{15}$ In this study, we used a validated abbreviated Chinese version which had previously been used in the evaluation of the quality of care among public and private primary clinics in Hong Kong. ${ }^{15}$ The measure contains 36 items, each rated on a 4-point Likert scale ( $1=$ definitely not; $2=$ probably not; $3=$ probably and $4=$ definitely), grouped into 9 domains.
An additional 'don't Know'/'cannot Remember' option was also provided for each item. The median value method assigns a value of 2.5 for those who answer 'don't Know'/'cannot remember'. The missing values were treated as 'don't know'/'cannot remember' option. The sum score was calculated as the sum of all the responses. The highest possible score for this short version PCAT is 144. The higher the score, the better the performance of the practice concerned.

All subjects completed a paper-based questionnaire consisting of the Chinese PCPCM, CARE, PEI, Adult (short version) PCAT and items on sociodemographics during the baseline recruitment visit. They were contacted 14 days later for a follow-up phone interview conducted by a trained research assistant to readminister the Chinese PCPCM.

\section{Data analyses}

To confirm that the items of the PCPCM are valid indicators of the underlying construct and that they share a common single factor so that the mean score of the response items can reliably reflect the personcentredness of the primary care practice concerned, we used Rasch analysis for dimensionality and item fit to assess the construct validity. The item fit was evaluated by using outfit mean square $(\mathrm{MnSq}$ ) and infit $\mathrm{MnSq}$ statistics. ${ }^{16}{ }^{17}$ Fit statistics within the range of 0.7 to 1.4 are considered good. ${ }^{18}$ Rasch person reliability measures the strength of the Cronbach's internal consistency reliability. A Rasch person reliability of $>0.8$ indicates strong reliability. Cross-validation of the Rasch model between the baseline interview and follow-up PCPCM scores was carried out. Spearman correlation between each item and total score was computed for item-scale correlation to assess the validity of the items. Cronbach's alpha was calculated to measure the internal reliability. Spearman correlations between the scores of PCPCM and those of CARE, PEI and the Adult (short version) PCAT were used to test convergent construct validity. Descriptive statistics, including mean, SD, percentage of lowest possible (floor) and highest possible (ceiling) scores were calculated. Test-retest reliability was calculated between the PCPCM scores at baseline and the 14-day follow-up. Intraclass correlation coefficient (ICC) was employed as the index of test-retest reliability. Between-group differences in PCPCM scores by years the patients had known their doctors, the likelihood of consulting the same doctor or nurse each time, frequency of using the clinic services in past 12 months, self-perceived health level and the number of illnesses consulted (for chronic illness patients only) were tested by independent sample t-tests.

All statistical analyses were performed using Winsteps V.4.5.1 and IBM SPSS V.26.0.

\section{Patient and public involvement}

Participants or the public were not involved in the design, or conduct, or reporting or dissemination plans of the research as that was deemed inappropriate. 


\section{RESULTS}

Three hundred subjects completed the baseline interview. During the data collection, we encouraged the subjects to administer the questionnaires by themselves outside the consultation room after their doctor consultations. About $50 \%$ of the subjects could complete the questionnaires on their own but the other $50 \%$ requested the help from our trained research assistant responsible for subject recruitment to read out the questions to them due to visual impairment or subjects' preference. The time needed for the subjects to complete the PCPCM ranged from 5 to 12 min. Generally speaking, it took the elderly patients more time to complete the Measure. The total time needed for the subjects to complete all the questionnaires (adding the demographics, CARE, PEI and PCAT) ranged from 15 to $35 \mathrm{~min}$. Characteristics of the patients are shown in table 1 . Of these, 118 patients were successfully interviewed by phone at 14 days after the first interview to assess the test-retest reliability of the PCPCM. We continued to call up the remaining subjects and eventually 292 subjects $(97.3 \%, \mathrm{~N}=300)$ completed the second interview (median 16 days, range $14-56$ days) to enable us to cross-validate the results between the baseline and the follow-up with the Rasch model. The percentages of missing data for items 1 to 11 were $0 \%, 0.33 \%, 0 \%, 4.00 \%, 0.33 \%, 2.00 \%$, $0.33 \%, 3.67 \%, 3.33 \%, 0.67 \%$ and $0 \%$, respectively. None of the subjects had missing responses for more than three PCPCM items and hence all responses were included in the final analysis.

\section{Construct validity}

All the item fits (both infit and outfit) of the Rasch model were very good (except for item 1 which had a marginally higher outfit value of 1.43). The variance explained by the measure was $51.7 \%$. The first factor extracted by Rasch analysis had an eigenvalue of 1.97 and this did not form a viable second dimension. It supported the unidimensionality of the PCPCM. ${ }^{19}$ The person reliability was 0.84 indicating a strong internal consistency and supported a single factor.

\section{Item-person map}

Figure 1 shows the conventional Rasch model personitem maps for the cross-validation between the baseline and the follow-up samples. They display the location and distribution of both items and patient scores on the same common logit metric. They show that the 11 items are distributed across a range of difficulty, as described on the item side of the maps. They show person scores spread across a wide range of responses, as shown on the person side of the maps.

The results of the baseline interview showed the item calibrations ranged from -1.20 to 1.45 logits and they were evenly spread with four of them above the average item measure (0.0), one at 0.0 and six below. This spread of items showed a good coverage of the construct under investigation. The follow-up data showed item calibrations ranged from -0.95 to 1.33 logits and they were also evenly
Table 1 Characteristics of the subjects participated in the Chinese PCPCM psychometric study in Hong Kong

\begin{tabular}{|c|c|}
\hline Characteristics $(\mathrm{N}=300)$ & No, (\%) \\
\hline \multicolumn{2}{|l|}{ Age group } \\
\hline $18-59$ & $172(57)$ \\
\hline 60 or above & $128(43)$ \\
\hline \multicolumn{2}{|l|}{ Gender } \\
\hline Male & $150(50)$ \\
\hline Female & $150(50)$ \\
\hline \multicolumn{2}{|l|}{ Education level } \\
\hline No formal education received & $11(4)$ \\
\hline Primary & $45(15)$ \\
\hline Secondary & $146(49)$ \\
\hline Tertiary & $98(32)$ \\
\hline \multicolumn{2}{|l|}{ Occupation } \\
\hline Professional or managerial & $16(5)$ \\
\hline Clerical work & $30(10)$ \\
\hline Labour work & $79(27)$ \\
\hline Retired & $93(31)$ \\
\hline Housewife & $43(14)$ \\
\hline Unemployed & $14(5)$ \\
\hline Others/not answered & $25(8)$ \\
\hline \multicolumn{2}{|l|}{ Consultation reason } \\
\hline Chronic disease(s) follow up & $149(50)$ \\
\hline Episodic illness(es) & $151(50)$ \\
\hline \multicolumn{2}{|c|}{$\begin{array}{l}\text { Regarded the consulted doctor as one's } \\
\text { family doctor }\end{array}$} \\
\hline Yes & $74(25)$ \\
\hline No & $226(75)$ \\
\hline \multicolumn{2}{|c|}{ Duration the patient had known the doctor } \\
\hline$<1$ year & $223(74)$ \\
\hline$\geq 1$ year & $77(26)$ \\
\hline
\end{tabular}

Likeliness to see the same doctor/nurse each time for consultation

$\begin{array}{ll}\text { Probably not or definitely not or not sure } & 188(63) \\ \text { Probably or definitely will } & 112(37)\end{array}$

Frequency of using GOPC services in the past 12 months

$\begin{array}{lr}0-2 \text { times } & 65(22) \\ >2 \text { times } & 235(78)\end{array}$

Self-perceived health level

Fair or poor 140 (47)

Good or very good or excellent $\quad 160(53)$

No of illness(es) consulted (for chronic No, (\%) patients only) $(n=149)$

$=1$

$>1$

GOPC, General Out-patient Clinic (the public primary care clinic system in Hong Kong); PCPCM, Person-Centred Primary Care Measure. 


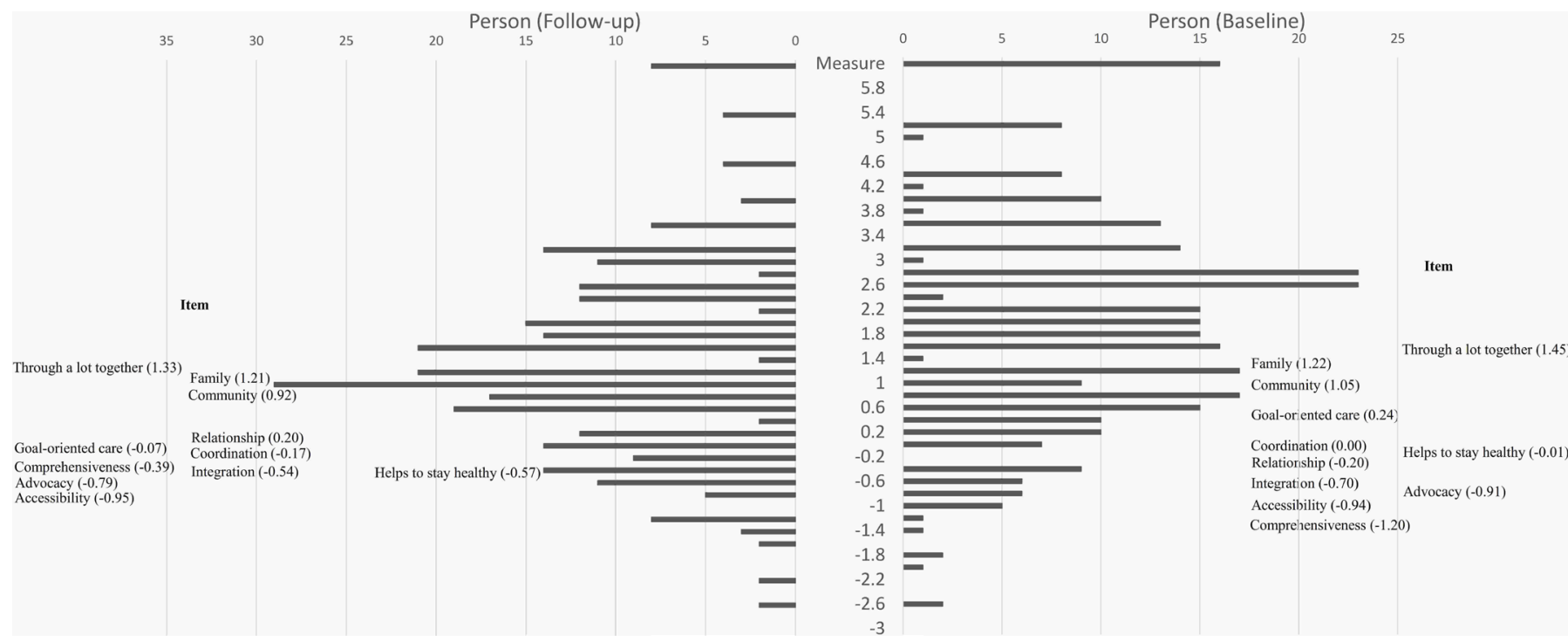

Figure 1 Rasch model for cross-validation of subjects in the first interview $(n=300)$ and follow-up $(n=292)$. Bars under person heading show distribution of person's responses across the range of difficulty of the items. Numbers in parentheses after each Item heading show distribution and lack of redundancy of items across the range of difficulty. Not pictured: On 'person (baseline)' side of map, mean=-1.80, $1 \mathrm{SD}=0.50$; for 'item', mean $=0,1 \mathrm{SD}=0.8$; on 'person (follow-up)' side of map, mean $=-1.18,1 \mathrm{SD}=1.71$; for 'item', mean=0, $1 \mathrm{SD}=0.76$.

spread with four of them above the average item measure $(0.0)$ and seven below. This spread of items also showed a good coverage of the construct under investigation.

The item-scale correlation between each item and the overall PCPCM score were all moderate to strong ( $\mathrm{r}=0.44$ $0.73)$, demonstrating a satisfactory internal consistency (table 2).

\section{Convergent construct validity}

The Chinese-PCPCM scores were significantly $(p<0.05)$ correlated with the scores of the Chinese CARE (0.58), PEI
(0.42) and Adult (short version) PCAT (0.48) measures supporting convergent construct validity (table 3 ).

\section{Reliability}

The Cronbach's alpha coefficient was 0.875 supported the internal reliability.

Among the patients ( $\mathrm{n}=118)$ who completed follow-up at 14 days from the first interview, $8.5 \%$ had the highest possible scores in the first interview but zero for lowest possible scores. During phone follow-up, there was a relatively lower proportion $(5.9 \%)$ of patients with ceiling

Table 2 Item-total score correlations corrected for overlapping of the Chinese PCPCM in the baseline interview

\begin{tabular}{|c|c|c|c|}
\hline \multirow[b]{2}{*}{ Item } & \multicolumn{3}{|c|}{ PCPCM score $(n=300)$} \\
\hline & Mean & (SD) & Correlation with the overall PCРCM score* \\
\hline 1. The practice makes it easy for me to get care. & 3.47 & $(0.70)$ & 0.44 \\
\hline $\begin{array}{l}\text { 3.In caring for me, my doctor considers all factors that } \\
\text { affect my health. }\end{array}$ & 3.28 & $(0.73)$ & 0.70 \\
\hline 5.This doctor or practice knows me as a person. & 3.12 & $(0.81)$ & 0.72 \\
\hline 6. My doctor and I have been through a lot together. & 2.61 & $(0.92)$ & 0.62 \\
\hline 7.My doctor or practice stands up for me. & 3.26 & $(0.72)$ & 0.70 \\
\hline $\begin{array}{l}\text { 8. The care I get takes into account knowledge of my } \\
\text { family. }\end{array}$ & 2.72 & $(0.91)$ & 0.56 \\
\hline 11. Over time, my practice helps me stay healthy. & 3.19 & $(0.79)$ & 0.72 \\
\hline
\end{tabular}


Table 3 Correlation between PCPCM item scores and scores of care, PEI and PCAT

\begin{tabular}{|llll}
\hline PCPCM items & CARE score & PEI score & PCAT score \\
\hline 1 & $0.16^{\star}$ & $0.13^{\star}$ & 0.11 \\
\hline 2 & $0.32^{\star}$ & $0.21^{\star}$ & $0.17^{\star}$ \\
\hline 3 & $0.48^{\star}$ & $0.35^{\star}$ & $0.36^{\star}$ \\
\hline 4 & $0.30^{\star}$ & $0.25^{\star}$ & $0.27^{\star}$ \\
\hline 5 & $0.52^{\star}$ & $0.38^{\star}$ & $0.38^{\star}$ \\
\hline 6 & $0.50^{\star}$ & $0.31^{\star}$ & $0.44^{\star}$ \\
\hline 7 & $0.44^{\star}$ & $0.27^{\star}$ & $0.29^{\star}$ \\
\hline 8 & $0.44^{\star}$ & $0.29^{\star}$ & $0.37^{\star}$ \\
\hline 9 & $0.43^{\star}$ & $0.23^{\star}$ & $0.41^{*}$ \\
\hline 10 & $0.45^{\star}$ & $0.34^{\star}$ & $0.48^{\star}$ \\
\hline 11 & $0.44^{\star}$ & $0.37^{\star}$ & $0.41^{\star}$ \\
\hline PCPCM score & $0.58^{\star}$ & $0.42^{\star}$ & $0.48^{\star}$ \\
\hline
\end{tabular}

Item A8, A9, E2 and M1 (questions regarding the background information of the respondents) in the PCAT are not involved in the computation of total PCAT score. Correlations between scores were evaluated by Spearman correlation test.

${ }^{*} \mathrm{P}<0.05$.

CARE, Consultation and Relational Empathy; PCAT, Primary Care Assessment Tool; PCPCM, Person-Centred Primary Care Measure; PEI, Patient Enablement Index.

scores. The PCPCM score demonstrated moderate reliability $(\mathrm{ICC}=0.622, \mathrm{p}<0.001)$.

\section{Sensitivity by known group comparison}

Sensitivity was measured by the ability of the Chinese PCPCM to detect a difference between known groups, tested by independent sample t test. The PCPCM scores were higher among the group of patients: (1) who had known the doctors $\geq$ one year; (2) who reported a higher likelihood of seeing the same doctor or nurse each time; (3) who used the clinic services more frequently $(>2$ times) in the past 12 months; (4) who perceived their health as 'good' or 'better' (table 4). There was no significant difference in the PCPCM scores between groups of patients who reported to have more than one chronic disease and those with only one chronic disease.

\section{DISCUSSION}

This was the first study to show the validity, reliability and sensitivity of the PCPCM in a Chinese population whose culture is very different from that of the population in which the measure was originally developed. The traditional Chinese doctor-patient relationship is often regarded as paternalistic, ${ }^{13}$ but an earlier study found that Hong Kong Chinese patients actually preferred personcentred consultations, regardless of their socioeconomic background. ${ }^{20}$ Chinese patients may not explicitly disagree with the doctor but they tend to express their dissatisfaction with their doctors by non-compliance to treatment and doctor shopping. ${ }^{21}$ The Chinese PCPCM
Table 4 Sensitivity of the Chinese PCPCM scores of the subjects by known groups

\begin{tabular}{|c|c|c|c|}
\hline Known groups & $\begin{array}{l}\mathrm{PCPCM} \text { score } \\
(\text { mean } \pm \mathrm{SD}, \mathrm{n})\end{array}$ & ES & $P$ value \\
\hline $\begin{array}{l}\text { No. of years the patient has known the } \\
\text { doctor }\end{array}$ & & & $<0.001$ \\
\hline$<1$ & $3.01 \pm 0.57(223)$ & 0.60 & \\
\hline$\geq 1$ & $3.32 \pm 0.46(77)$ & & \\
\hline $\begin{array}{l}\text { Likeliness to see the same doctor/nurse } \\
\text { each time for consultation }\end{array}$ & & & 0.001 \\
\hline $\begin{array}{l}\text { Probably not or definitely not or not } \\
\text { sure }\end{array}$ & $3.01 \pm 0.57(188)$ & 0.40 & \\
\hline Probably or definitely will & $3.23 \pm 0.51(112)$ & & \\
\hline $\begin{array}{l}\text { Frequency of using GOPC services in the } \\
\text { past } 12 \text { months }\end{array}$ & & & 0.002 \\
\hline $0-2$ times & $2.90 \pm 0.57(65)$ & 0.43 & \\
\hline$>2$ times & $3.14 \pm 0.55(235)$ & & \\
\hline Self-perceived health level & & & 0.001 \\
\hline Fair or poor & $2.97 \pm 0.57(140)$ & 0.39 & \\
\hline Good or very good or excellent & $3.19 \pm 0.53(160)$ & & \\
\hline $\begin{array}{l}\text { No of illness(es) consulted (for chronic } \\
\text { patient only) }\end{array}$ & & & 0.413 \\
\hline$=1$ & $3.27 \pm 0.44(93)$ & 0.14 & \\
\hline$>1$ & $3.20 \pm 0.55(56)$ & & \\
\hline \multicolumn{4}{|l|}{ Reason for consultation } \\
\hline Chronic disease(s) follow up & $3.24 \pm 0.51(149)$ & 0.55 & \\
\hline Episodic illness(es) & $2.94 \pm 0.57(151)$ & & $<0.001$ \\
\hline
\end{tabular}

ES, effect size effect size is estimated by Cohen's d; GOPC, General Out-patient Clinic (the public primary care clinic system in Hong Kong); PCPCM, Person-Centred Primary Care Measure.

has the potential to identify patients who needs to be specifically encouraged to express their opinions on their experience in primary care practices.

\section{Strengths of the study}

The strength of the study is that the translation equivalence and content validity of the Chinese PCPCM was assured by a previous study by the same team. ${ }^{6}$

This current study demonstrated that Chinese patients aged from 18 to 85 years, of either sex and with varying education levels could understand, correctly interpret and respond to all the items of the Chinese PCPCM. The Chinese PCPCM showed good construct validity as indicated by the Rasch analysis showing unidimensionality structure with all items loading on one factor, good item fit, excellent person reliability and item reliability. These results were similar to the findings from the validation study of the original English measure (with item fit ranging from 0.55 to 1.49 for the combined clinical sample). The item reliability of the Chinese PCPCM was similar to that of the original English version of 0.98 (for the combined clinical sample). ${ }^{3}$ All Chinese PCPCM items showed moderate to strong positive associations with the factor, akin to the results of the original study. ${ }^{3}$ These findings supports the cross-cultural validity of the PCPCM in the Chinese population. The Cronbach's 
alpha of this study was 0.875 was also in line with that of the original English measure with an average $0.93 .{ }^{3}$ The correlations between the scores of the Chinese-PCPCM and those of the Chinese CARE, PEI and Adult (short version) PCAT measures were weak to moderate $(\mathrm{r}=0.11-$ 0.58 ) although mostly significant, suggesting that the measures are related but not identical in construct for patient-perceived quality of care. The Chinese PCPCM measures a broader spectrum of person-centred elements of the practice, while the CARE, PEI and Adult (short version) PCAT each measures a specific aspect of process or outcome of care. All PCPCM items were pertinent and crucial as indicated by the high correlations with the total PCPCM score. The treasured areas of primary care are not always attained by clinical processes or outcomes but to evaluate primary care as a whole.

The proportion of respondents scoring the lowest and highest scores were all $<10 \%$, indicating no floor or ceiling effects. ${ }^{22}$ The measure was also found to be reliable in both internal consistency and test-retest reliability. These results suggest that the Chinese PCPCM is very likely to be sensitive in distinguishing differences between different primary care practices and responsive to changes with time or interventions in any individual practice.

\section{Sensitivity and comparison with literature}

The Chinese PCPCM was able to detect a significant difference between known groups, as expected. The observation of higher PCPCM scores reported by patients who had known the doctors for a longer time $(\geq 1$ year) also supported the external construct validity of the PCPCM, which was consistent with the findings in the literature. ${ }^{2324}$ The PCPCM scores were also found to be higher in patients who consulted for chronic illnesses than those for episodic conditions. As chronic illnesses entailed continuity of care that enables the doctor to address the wider needs of the person, this in return promoted higher patient satisfaction. ${ }^{24-26}$ Higher PCPCM scores were also observed in patients with better selfperceived health condition. Although this cross-sectional study could not establish a causal relationship, evidence from past research showed that patients who perceived themselves to be in good health would project the sense of well-being with their health-related environment. ${ }^{27}$

\section{Lower response rates to individual items}

In our study, we noticed the response rates to items 4 , 8 and 9 were lower among all the items. The percentages of missing data for these items were $4.00 \%, 3.67 \%$, $3.33 \%$, respectively. Item 4 enquired the role of the primary care practice being a coordinator of the care a patient got from multiple places, while items 8 and 9 assessed how the knowledge of the practice towards the patient's family and the community had affected the quality of the primary care offered. We believed the lower response rates to these items were due to subjects feeling the questions were not directly relevant to them if they did not have complex medical problems requiring coordination (item 4), or did not have complicated family or community issues (items 8 and 9). This is actually coherent with the findings of our previous cognitive debriefing study of the Chinese translation of the PCPCM in which the average content validity index on relevance of items eight and nine were both relatively low at $0.55{ }^{6}$

\section{Implications}

The world's largest ethnic group is Han Chinese. ${ }^{28}$ The confirmation of the validity, reliability and sensitivity of the Chinese PCPCM will enable the instrument to be more widely used internationally. It can be used for audit and continuous quality improvement of primary care practices and clinicians. This measure goes much further focusing on areas of care that promote patient perceptions on the incorporation, prioritisation and personalising roles of primary care, which is measured by the most reliable and accurate user, that is, the patient. ${ }^{3}$ The Chinese PCPCM can be used in the training of primary care doctors to change the paradigm from the focus on specific doctor-centred care processes, which is prevalent in our culture, to broader evaluations of primary care. $^{329-34}$ The total score as well as individual items could be used as information on areas where further attention, support and enhancement are needed for doctors and the healthcare system. ${ }^{3}$

\section{Limitations and suggestions for future studies}

The intention of using two different methods for data collection in the first interview (self-administered questionnaire onsite) and follow-up (telephone interview) was indeed a compromise in order to minimise the patient's burden for participation. The possibility that respondents might have applied less mental effort when they did the telephone follow-up ${ }^{35}$ had been thoroughly balanced against subjects' burden. Readers should hence note that telephone follow-up may account for the variation in retest results. ${ }^{37}$

We also recognised that some other factors with possible correlation with person-centred primary care had not been investigated, for example, doctor's communication skills, length of consultation and how well the doctor and the patient know each other, etc. Future studies should also be performed to explore the criterion-referenced validity of the PCPCM to determine if the scores are good predictors for patient outcomes.

Moreover, our study only involved subjects in Hong Kong, and recruitment was just from a single primary care clinic. Although the study subjects were representative of the spectrum of public primary care patients in Hong Kong, the results may not be generalisable to Chinese patients attending private practices or living in other parts of the world due to different environmental and social context. Further testing in other Chinese populations is recommended. 


\section{CONCLUSION}

This pilot study was the first to establish the construct validity and reliability of the Chinese PCPCM. The PCPCM scores were significantly higher in patients who had known the doctors for a longer period of time $(\geq 1$ year), consulting for chronic illnesses and self-perceived to have better health condition supporting sensitivity. Since our study population included a wide range of age, gender, education level and social class, it is suggested that the PCPCM is valid for use with the general Hong Kong Chinese population. Further studies to investigate the sensitivity in differentiating outcomes in distinct settings or morbidity groups and responsiveness to changes with intervention still need to be carried out to evaluate the applicability of the Chinese PCPCM as an outcome measure on quality and effectiveness of primary care.

\section{Author affiliations}

${ }^{1}$ Department of Family Medicine and Primary Care, The University of Hong KongShenzhen Hospital, Shenzhen, China

${ }^{2}$ Department of Family Medicine and Primary Care, The University of Hong Kong Li Ka Shing Faculty of Medicine, Hong Kong, China

${ }^{3}$ Department of Pharmacology and Pharmacy, The University of Hong Kong Li Ka Shing Faculty of Medicine, Hong Kong, China

${ }^{4}$ Department of Family Medicine and Population Health, Virginia Commonwealth University School of Medicine, Richmond, Virginia, USA

${ }^{5}$ Center for Community Health Integration, Case Western Reserve University School of Medicine, Cleveland, Ohio, USA

Acknowledgements We would like to thank Professor Stewart W Mercer and Dr Colman SC Fung for their permission to use the Chinese version of the CARE Measure in our study. Thanks to Professor Leiyu Shi of Johns Hopkins University and Professor Samuel YS Wong of the Chinese University of Hong Kong in allowing us to use the Chinese Adult (short version) PCAT. Thanks also go to Lam Sau Mei Joyce, our project's research assistant, who made a significant contribution to the implementation of the study, collection of the research data, statistical analysis, results interpretation and manuscript drafting. Appreciation also goes to Ivan $\mathrm{Au} C \mathrm{Chi}$ Ho for his contribution to the statistical analysis.

Contributors ETYT and CLKL contributed to study design, acquisition of data and writing of the manuscript. CKHW and SJZ contributed to the statistical analysis, interpretation of results and writing of the manuscript; WYC, RSE and KCS contributed to interpretation of results, review and editing of the manuscript.

Funding This work was supported by the New Staff Start-up Package granted by The University of Hong Kong Li Ka Shing Faculty of Medicine. Grant number is not applicable.

Competing interests None declared.

Patient consent for publication Not required.

Ethics approval Institutional Review Board of the University of Hong Kong/Hospital Authority Hong Kong West Cluster (HKU/HA HKW IRB) HKU/HA HKW IRB reference number UW 18-492.

Provenance and peer review Not commissioned; externally peer reviewed.

Data availability statement Data are available upon reasonable request. The datasets used and/or analysed during the current study are available from the corresponding author on reasonable request.

Supplemental material This content has been supplied by the author(s). It has not been vetted by BMJ Publishing Group Limited (BMJ) and may not have been peer-reviewed. Any opinions or recommendations discussed are solely those of the author(s) and are not endorsed by BMJ. BMJ disclaims all liability and responsibility arising from any reliance placed on the content. Where the content includes any translated material, BMJ does not warrant the accuracy and reliability of the translations (including but not limited to local regulations, clinical guidelines, terminology, drug names and drug dosages), and is not responsible for any error and/or omissions arising from translation and adaptation or otherwise.
Open access This is an open access article distributed in accordance with the Creative Commons Attribution Non Commercial (CC BY-NC 4.0) license, which permits others to distribute, remix, adapt, build upon this work non-commercially, and license their derivative works on different terms, provided the original work is properly cited, appropriate credit is given, any changes made indicated, and the use is non-commercial. See: http://creativecommons.org/licenses/by-nc/4.0/.

\section{ORCID iDs}

Emily Tsui Yee Tse http://orcid.org/0000-0001-7409-9507

Carlos King Ho Wong http://orcid.org/0000-0002-6895-6071

Weng Yee Chin http://orcid.org/0000-0003-3171-6792

\section{REFERENCES}

1 World_Health_Organization, Unicef. A vision for primary health care in the 21st century, 2018.

2 Starfield B. Is patient-centered care the same as person-focused care? Perm J 2011;15:63-9.

3 Etz RS, Zyzanski SJ, Gonzalez MM, et al. A new comprehensive measure of high-value aspects of primary care. Ann Fam Med 2019;17:221-30.

4 Etz RS SK. Person-centered primary care measure. The larry A. green center, 2020. Available: https://www.green-center.org/pcpcm [Accessed 22 Jan 2021].

5 Index_Mundi. World demographics profile 2020, 2020. Available: https://www.indexmundi.com/world/demographics_profile.html [Accessed 22 Jan 2021].

6 Tse ETY, Lam CLK, Wong CKH, et al. Cultural adaptation and content validity of a chinese translation of the 'person-centered primary care measure': findings from cognitive debriefing. Fam Med Community Health 2020;8:e000621.

7 Population By-census Office Census and Statistics Department - The Government of the Hong Kong Special Administrative Region. 2016 population by-census summary results, 2016. Available: https://www. statistics.gov.hk/pub/B11200942016XXXXB0100.pdf [Accessed 22 Jan 2021].

8 Mercer SW, Maxwell M, Heaney D, et al. The consultation and relational empathy (care) measure: development and preliminary validation and reliability of an empathy-based consultation process measure. Fam Pract 2004;21:699-705.

9 Mercer SW, McConnachie A, Maxwell M, et al. Relevance and practical use of the consultation and relational empathy (care) measure in general practice. Fam Pract 2005;22:328-34.

10 Mercer SW, Reynolds WJ. Empathy and quality of care. Br J Gen Pract 2002;52 Suppl:S9-12.

11 Fung CSC, Hua A, Tam L, et al. Reliability and validity of the chinese version of the CARE Measure in a primary care setting in hong kong. Fam Pract 2009;26:398-406.

12 Howie JG, Heaney DJ, Maxwell M, et al. A comparison of a patient enablement instrument (PEI) against two established satisfaction scales as an outcome measure of primary care consultations. Fam Pract 1998;15:165-71.

13 Lam CLK, Yuen NYK, Mercer SW, et al. A pilot study on the validity and reliability of the patient enablement instrument (PEI) in a Chinese population. Fam Pract 2010;27:395-403.

14 Yang $\mathrm{H}$, Shi L, Lebrun LA, et al. Development of the chinese primary care assessment tool: data quality and measurement properties. Int $J$ Qual Health Care 2013;25:92-105.

15 Wong SYS, Kung K, Griffiths SM, et al. Comparison of primary care experiences among adults in general outpatient clinics and private general practice clinics in Hong Kong. BMC Public Health 2010;10:397.

16 Bond T, Fox CM. Applying the rasch model: fundamental measurement in the human sciences. Routledge, 2013.

17 Linacre JM. A user's guide to WINSTEPS $®$ MINISTEP rasch-model computer programs program manual 4.8.0, 2021. Available: 10.1093/ intqhc/mzs072 [Accessed 22 Jan 2021].

18 Linacre JM. Fit diagnosis: infit outfit mean-square standardized, 2020. Available: https://www.winsteps.com/winman/misfitdiagnosis. htm [Accessed 22 Jan 2021].

19 Linacre JM. Dimensionality: contrasts \& variances, 2020. Available: https://www.winsteps.com/winman/principalcomponents.htm [Accessed 22 Jan 2021].

20 Smith D, Dixon A, Lam C. Hong Kong patients' preferences for physician communication style. In: Smith $\mathrm{DH}$, ed. Health communication and China. The Health Communication Initiative, 1998.

21 Chin WY, Wong $\mathrm{CKH}, \mathrm{Ng} \mathrm{CCW}$, et al. Cultural adaptation and psychometric properties of the chinese burden of treatment 
questionnaire $(\mathrm{C}-\mathrm{TBQ})$ in primary care patients with multi-morbidity. Fam Pract 2019;36:657-65.

22 McHorney CA, Ware JE, Lu JF, et al. The mos 36-item shortform health survey (SF-36): III. tests of data quality, scaling assumptions, and reliability across diverse patient groups. Med Care 1994;32:40-66.

23 Schers $\mathrm{H}$, Webster $\mathrm{S}$, van den Hoogen $\mathrm{H}$, et al. Continuity of care in general practice: a survey of patients' views. $\mathrm{Br} J$ Gen Pract 2002;52:459-62.

24 Saultz JW, Albedaiwi W. Interpersonal continuity of care and patient satisfaction: a critical review. Ann Fam Med 2004;2:445-51.

25 Schers $\mathrm{H}$, van den Hoogen $\mathrm{H}$, Bor $\mathrm{H}$, et al. Familiarity with a GP and patients' evaluations of care. A cross-sectional study. Fam Pract 2005;22:15-19.

26 Sun KS, Lam TP, Lam KF, et al. Do patients with and without a regular primary care physician have their psychological distress looked after differently? J Public Health 2019;41:399-404.

27 Xiao H, Barber JP. The effect of perceived health status on patient satisfaction. Value Health 2008;11:719-25.

28 Wikipedia. Demographics of the world, 2021. Available: https://en. wikipedia.org/wiki/Demographics_of_the_world [Accessed Feb 28 2021].

29 Jerant A, Fenton JJ, Franks P. Primary care attributes and mortality: a national person-level study. Ann Fam Med 2012;10:34-41.
30 DeVoe JE, Tillotson CJ, Wallace LS, et al. Parent and child usual source of care and children's receipt of health care services. Ann Fam Med 2011;9:504-13.

31 Ettner SL. The timing of preventive services for women and children: the effect of having a usual source of care. Am J Public Health 1996;86:1748-54.

32 DeVoe JE, Petering R, Krois L. A usual source of care: supplement or substitute for health insurance among low-income children? Med Care 2008;46:1041.

33 Nothelle SK, Boyd C, Sheehan O, et al. Factors associated with loss of usual source of care among older adults. Ann Fam Med 2018;16:538-45.

34 Villani J, Mortensen K. Nonemergent emergency department use among patients with a usual source of care. J Am Board Fam Med 2013;26:680-91.

35 Holbrook AL, Green MC, Krosnick JA. Telephone versus face-to-face interviewing of national probability samples with long questionnaires - comparisons of respondent satisficing and social desirability response bias. Public Opin Q 2003;67:79-125.

36 Singleton R, Straits BC. Survey interviewing. In: The SAGE handbook of interview research: the complexity of the craft. , 2012: 2, 77-98.

37 Molina JA, Lim GH, Seow E, et al. Effects of survey mode on results of a patient satisfaction survey at the observation unit of an acute care hospital in Singapore. Ann Acad Med Singap 2009;38:487-93. 